\title{
Marco teórico para la planificación estratégica y gestión del proceso de promoción de centros comerciales
}

\author{
Aliane Vieira de Castro ${ }^{1}$ | Gema María Ramírez Pacheco ${ }^{2}$ | Fco. Javier Neila González ${ }^{3}$
}

Recibido: 03-07-2019 | en su versión final: 02-12-2019

Resumen

\begin{abstract}
La promoción de centros comerciales es una actividad compleja que abarca un amplio abanico de actividades multidisciplinares e implica un análisis de riesgo específico. Con objeto de evitar riesgos proyectuales y maximizar los resultados del proyecto, es necesario gestionar la interrelación entre las etapas del ciclo de vida de la promoción, a partir de un conocimiento exhaustivo de los objetivos estratégicos. Sin embargo, según Peiser y Halmilton (2012), muchos promotores no diseñan formalmente un plan estratégico, basándose la toma de decisiones en análisis. Por ello, esta investigación tiene por objetivo crear un marco organizacional y sistémico que conecte la planificación estratégica a las actividades que engloba el desarrollo de la promoción de centros comerciales. El marco conceptual propuesto abarca cuatro fases principales: Definición de la estrategia de negocio, Predesarrollo, Desarrollo del negocio y Gestión del negocio. Este sistema de análisis permite, no sólo entender como las diferentes actividades interactúan con la estrategia de negocio, sino también establece las futuras expectativas de los grupos de interés. Además, dicho marco puede incorporarse a futuras investigaciones en el ámbito del desarrollo estratégico de negocios inmobiliarios, gestión de proyectos y modelos de viabilidad. De este modo, el promotor podrá visualizar, de acuerdo con su campo de actuación, el resultado de cada estrategia por nivel negocio (empresa-cartera de inversión-edificio), así como de forma conjunta. Además, proporciona una visión total de la cadena de valor del edificio, en la que se puede diseñar las acciones pertinentes para la creación de valor.
\end{abstract}

Palabras clave: Mercado inmobiliario; gestión de proyecto; centros comerciales; promoción inmobiliaria

Citación

Vieira de Castro, A. et al. (2020). Marco teórico para la planificación estratégica y gestión del proceso de promoción de centros comerciales, ACE: Architecture, City and Environment, 14(42)), 8748. DOI: http://dx.doi.org/10.5821/ace.14.42.8748

\footnotetext{
1 Dra. Arquitecta, Universidad Politécnica de Madrid, ETSAM (ORCID ID: 0000-0003-0678-2878), ${ }^{2}$ Dra. Arquitecta, Universidad Politécnica de Madrid, Profesora Ayudante Doctor, ETSAM (ORCID ID: 0000-00033461-0811), ${ }^{3}$ Dr. Arquitecto, Catedrático de Universidad, Universidad Politécnica de Madrid, ETSAM (ORCID ID: 0000-0002-2645-8656, Researcher ID: X-7218-2019). Correo de contacto: alianevdec@gmail.com
}

ACE, 14 (42) CC BY-ND 3.0 ES | UPC Barcelona, España | Marco teórico para la planificación estratégica y gestión del proceso de promoción de centros comerciales. DOI: http://dx.doi.org/10.5821/ace.14.42.8748 


\title{
A theoretical framework for the strategic planning and management of the shopping centre's development process
}

\begin{abstract}
The shopping centre's development is a complex activity that encompasses a range of multidisciplinary activities and involves a specific risk analysis. Therefore, in order to maximize the results and avoid project risks, it is necessary not only to manage the interrelation between the stages of the life cycle of the promotion, but also to have an exhaustive knowledge of the strategic objectives of the promoter. Nevertheless, according to Peiser and Halmilton (2012), usually, many developers do not formally design a strategic plan and their personal experiences tend to drive decision making instead of the prescribed analysis. Thus, this exploratory research proposes to create an organizational and systemic framework that interconnects strategic planning with the shopping centre's development activities. The proposed conceptual framework covers four main phases: Definition of the business strategy, Pre-development, Business development and Business management. This analysis allows the professionals not only to understand how these activities interact with the business strategy, but also to evidence the future expectations of the stakeholders. In addition, this framework can support future research in the field of strategic development of real estate businesses, project management and feasibility models. Besides, its flexible structure allows professionals to adapt the suggested model to the development process of all types of real estate assets (e.g. offices, hotels, residential). For this, the developer can visualize, according to its field of action, the result of each strategy, in each level of the business (company - investment portfolio - building) separately, as well as jointly the total decisions results. In addition, it provides a full view of the building's value chain, in which the professional can design the relevant actions for value creation.
\end{abstract}

Keywords: Real estate; Project management; shopping centres; property development process

\section{Introducción}

En la actualidad, los centros comerciales tradicionales ${ }^{1}$ son establecimientos complejos y dinámicos que comprenden una amplia gama de actividades, no sólo vinculada a la venta de bienes y servicios, sino también al ocio, salud y bienestar de los consumidores. En la última década su configuración arquitectónica y modelo de negocio viene sufriendo significativas modificaciones debido a los nuevos hábitos de los clientes, la evolución tecnológica y el crecimiento de las compras online (Kramer, 2008;

\footnotetext{
1 Los centros comerciales con fines no específicos son clasificados como formatos tradicionales por la European Research Group de ICSC. Dichos centros tienen una mezcla comercial diversificada con artículos que los consumidores compran con regularidad tales como, ropa y calzado, electrónica, perfumería, juguetes, artículos de lujo, regalos y alimentación, entre otros. Hoy en día, de acuerdo con su estrategia de negocio y cadena locomotora, ofrecen ocio y cuidados a la salud, así como otros tipos de servicios como supermercado. Pueden ser tanto un negocio desarrollado al aire libre como en un espacio cerrado y estar clasificado por su tamaño como muy grande, grande, mediano y pequeño (ICSC, 2014; AECC, 2019) Sin embargo, a veces no es posible clasificar con exactitud un centro comercial debido a sus características híbridas. La industria es dinámica y los centros suelen combinar elementos de dos o más clasificaciones básicas para mantener su competitividad. Por ello, según International Council of Shopping Centers (ICSC, 2004), un centro comercial puede abarcar más de una tipología clave, pudiéndose plantear una futura revisión de las clasificaciones.
} 
Mckinsey, 2014). En este sentido, los edificios deben convertirse en espacios atractivos capaces de mejorar la experiencia de compra, así como inspirar las decisiones de aquellos que visitan el centro.

Por ello, la promoción de centros comerciales es una actividad multidisciplinar que implica procedimientos diferenciales con respecto a otros tipos de promociones inmobiliarias (Geltner et al., 2014; Neves et al., 2014). A lo largo de las diferentes fases que constituyen el proceso de promoción, se deben tomar importantes decisiones, multidimensionales que están conectadas a la planificación estratégica de la empresa promotora. Además, es un proceso dinámico y complejo en el que se ven involucrada una gran variedad de profesionales técnicos y recursos físicos en un tiempo limitado (White et al., 1996).

De este modo, los profesionales responsables de la gestión del proceso necesitan interrelacionar las etapas del ciclo de vida de la promoción, para poder medir correctamente los riesgos y oportunidades del negocio. Necesitan tener un conocimiento exhaustivo de los objetivos estratégicos diseñados por el promotor, con el objeto de maximizar los resultados y evitar riesgos proyectuales. Es decir, los distintos niveles jerárquicos de la promoción deben definir dos factores claves para garantizar el éxito del negocio: [1] cómo la estrategia empresarial se incorpora a la estrategia del nuevo proyecto; y [2] cuáles son los mecanismos a incorporar para alcanzar la oportunidad del nuevo negocio. Por ello, la estrategia empresarial debe traducirse en la estrategia del proyecto, siendo importante definir la gestión del proyecto dentro del contexto de la gestión del negocio.

No obstante, según Peiser y Halmilton (2012), por lo general, muchos promotores no diseñan formalmente un plan estratégico, sino que únicamente incorporan como estrategia parámetros específicos como el mercado demográfico, el crecimiento del PIB o el tipo de localidad. De este modo, muchas empresas llevan a cabo proyectos que quizá surjan sin una acción planificada integralmente. Sin embargo, en un mercado cíclico y sensible a los cambios socioeconómicos, planificar hacia dónde dirige la empresa cada negocio, es fundamental para aprovechar al máximo las oportunidades, adelantar riesgos e impactos, así como evitar posibles pérdidas de cuotas de mercado y rentabilidad.

Otro factor de impacto es la subjetividad existente en torno a la estructura del proceso de promoción. La experiencia personal de los profesionales impulsa la toma de decisiones en lugar de basarse en análisis previos o investigaciones en el ámbito. La falta de un marco unificado y flexible capaz de adaptarse a las variables de cada proyecto conduce a los promotores a la toma de decisiones arriesgadas (Fisher y Collins, 1999; Kohlhepp, 2012). Según Kohlhepp (2012), los modelos conceptuales utilizados para describir el desarrollo inmobiliario llevan a confusión, frustración, duplicidad y riesgos extraordinarios, ya que los profesionales tienen una comprensión diferente de la naturaleza del proceso. Además, la integración de las diferentes etapas no suele considerarse en su globalidad en la fase de toma de decisiones.

De este modo, el proceso de promoción necesita, no sólo la constante interacción entre los grupos de interés (inversores/promotores, ocupantes/inquilinos y el sector público), sino también una organización dinámica de sus actividades. Este modelo posibilita una visión integral, evitando riesgos de rendimientos operacionales negativos del centro comercial. A fin de desarrollar modelos de uso práctico de gestión, muchos investigadores se han concentrado en la organización del proceso y definición de un marco de actividades. Sin embargo, existe un limitado desarrollo respecto a las etapas dentro del sector comercial, no estableciéndose la importancia de su integración y vinculación a la planificación estratégica de la empresa para conducir la toma decisiones. Otro tema para destacar es que muchas veces los promotores simplemente tratan de gestionar el proceso a partir de la evaluación financiera, utilizando el flujo de efectivo esperado como base de análisis, aunque esto proporcione una visión insuficiente para guiarlos en la gestión de riesgos a través del proceso. 
Bajo este contexto, el objetivo de presente investigación es crear un marco organizacional y sistémico que interconecte la estrategia empresarial a las actividades claves del proceso de la promoción de los centros comerciales tradicionales. La investigación busca proporcionar una visión holística y secuencial de las etapas y actividades, las características intrínsecas de cada actividad, así como la interrelación entre ellas. Por ello, dicho trabajo exploratorio está dirigido a investigadores y profesionales que participan activamente en el proceso de toma de decisiones durante proceso planificación, control y gestión de la operación inmobiliaria.

\section{Antecedentes}

Por lo general, la falta de una ordenación sistémica deriva de las distintas percepciones sobre las fases que estructuran el proceso de promoción de un bien inmueble, dadas las múltiples y diversas variables que condicionan los proyectos. Según Reed y Wilkinson (2012), esto se justifica en parte por la gran variabilidad de las características intrínsecas de localización y por el alto número de tipos de activos inmobiliarios existentes. No obstante, existen otros motivos.

Cuando se compara la estructura de los marcos existentes, las actividades están agrupadas en fases o ciclos que casi nunca presentan la misma denominación, nomenclatura y orden. En este sentido, dichos marcos establecen una amplia cantidad de actividades, que en ocasiones resultan repetitivas y confusas, centrándose en detallar y discutir los eventos individualmente sin secuenciarlos o crear una conexión temporal entre las actividades. Por otro lado, tampoco describen cómo dichas actividades influyen en la toma de decisiones estratégicas de la empresa promotora.

De acuerdo con la revisión bibliográfica (Birrell y Gao, 1997; Peiser et al., 2012; Kohlhepp, 2012; Reed y Wilkinson, 2012), se puede definir el proceso de promoción como una actividad que opera una cadena de eventos infinitamente flexibles y que abarcan acciones que a menudo pueden superponerse e interactuar. De modo general, estos eventos pueden agruparse en cuatro etapas claves (Figura 1).

Sin embargo, para Graaskamp (1981) y Miles et al. (2000) el punto de inicio del proceso seria la toma de decisión de desarrollar la promoción de un activo inmobiliario. Se plantea iniciar el proceso con una etapa que da origen a la idea de proyecto, donde el estudio de mercado en conjunto con la experiencia y conocimiento general del promotor sobre legislación, construcción, finanzas y derecho inmobiliario son los insumos para la concepción del concepto general del producto inmobiliario.

Tras ello, un análisis de mercado más detallado direcciona la elección a una localización, determinando la viabilidad de un proyecto en un punto específico. Estas tareas definen las posibles áreas de implantación, caracterizándolas a nivel socioeconómico urbanístico y físico, lo que permite establecer las más apropiadas para maximizar la rentabilidad del activo inmobiliario.

Tras esto, se desarrollaría el estudio de viabilidad que determina la factibilidad del proyecto. Es cuando el promotor/inversor decide invertir o no en el negocio conceptualizado (Birrell y Gao., 1997; Miles et al., 2000; Peiser y Halmilton, 2012). Según Peiser y Halmilton. (2012), la toma de decisión de continuar con el desarrollo de la promoción debe estar basada en linformaciones cada vez más precisas que dotan al proyecto de la suficiente confianza para invertir en él. Por ello, estas actividades iniciales agrupadas en una fase de predesarrollo deben realizarse de acuerdo al diseño estratégico del proyecto (Morris y Jamieson, 2004).

En la fase de desarrollo de la promoción, para algunos autores (Miles et al., 2000; Peiser y Halmilton, 2012), las actividades de preparación para el periodo de ocupación del edificio, tales como contratación de los servicios de gestión, mantenimiento y obtención de permisos de ocupación, se sobreponen a las actividades de finalización de la construcción del edificio. Para Birrell y Gao (1997),

ACE, 14. (42) CC BY-ND 3.0 ES | UPC Barcelona, España | Marco teórico para la planificación estratégica y gestión del proceso de promoción de centros comerciales. DOI: http://dx.doi.org/10.5821/ace.14.42.8748 
Peiser y Halmilton, (2012) y Kohlhepp (2012), la última fase del proceso de promoción de un activo inmobiliario sería el momento de estabilización de su rendimiento tras la venta o remodelación de sus espacios. Para estos autores, el activo inmobiliario cuya base de explotación es el alquiler, como son los centros comerciales, necesita adecuarse siempre a las necesidades de la demanda para mantener su rentabilidad. Por lo tanto, el promotor debe analizar la importancia de este negocio en su cartera de activos, para decidir venderlo o reposicionarlo en su segmento de mercado.

Figura 1. Las etapas del proceso de promoción inmobiliaria

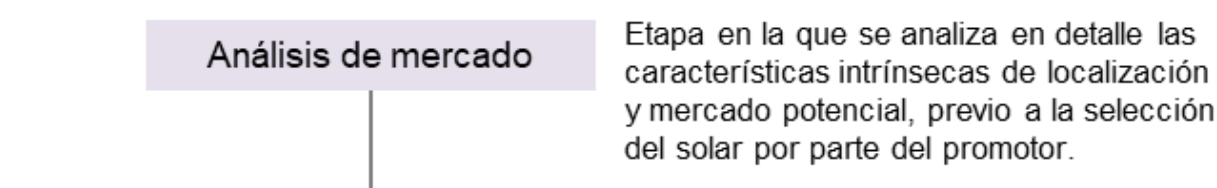

Etapa en la que se analiza en detalle las cacteristicas intrínsecas de localización del solar por parte del promotor.
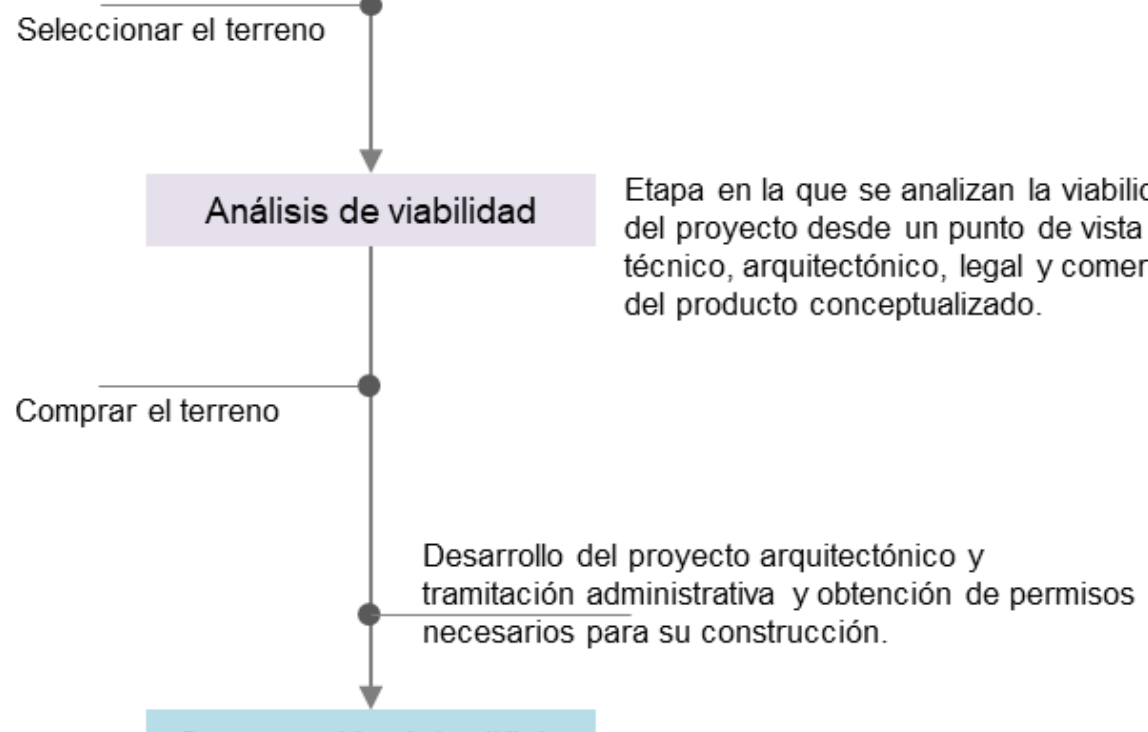

Construcción del edificio

Alquilar la Superficie

bruta alquilable (SBA)

\section{Operatividad del edificio}

Etapa en la que se construye el edificio

Etapa en la que se pone en marcha el inmueble debiendo gestionar su ocupación y los gastos e ingresos derivados del arrendamiento de sus superficies brutas alquilables (SBA).

Fuente: Elaboración propia a partir de Birrell y Gao (1997), Peiser et al. (2012), Kohlhepp (2012) y Reed y Wilkinson, (2012).

En la misma línea, Rocha lima (1996), divide el proceso de promoción de oficinas y centros comerciales en cuatro ciclos: [1] Ciclo de definición; engloba la definición de la estructura del proyecto de emprendimiento y su planificación; [2] Ciclo de implantación; es fase de la construcción del edificio 
y del inicio de la operatividad del mismo con la contratación de los servicios que sean requeridos; [3] Ciclo de operatividad; en este ciclo se entiende que el edificio mantiene su capacidad de explotación y generación de beneficios, siendo las actividades que lo definen la gestión del activo; [4] Ciclo de agotamiento; relativo al momento en que el proyecto de emprendimiento necesita remodelación o expansión para mantener su capacidad de generar beneficios.

No obstante, Kohlhepp (2012) enfatiza que las etapas mencionadas son insuficientes cuando se analiza el actual escenario del mercado inmobiliario a nivel mundial, centrado con frecuencia en remodelar edificios existentes, regenerar áreas urbanas ya consolidadas y desarrollar expansiones urbanas de usos mixtos en zonas aún no urbanizadas. Por ello, se propone incorporar a las variables del negocio de la fase inicial de la promoción, las actividades en donde sucede los eventos de planificación del suelo, urbanización y reparcelación, de acuerdo a los instrumentos de planeamiento correspondientes, ya que constituyen hitos relevantes en adquisición de valor del suelo.

No obstante, no se ha encontrado ningún estudio que analice en detalle las actividades propias inherentes a la promoción de centros comerciales. En la revisión realizada se detecta que no existen las propuestas necesarias para incorporar la planificación estratégica del negocio o estrategia de inversión al proceso de promoción y gestión del proyecto. La falta de un marco estandarizado y claro sobre las etapas del proceso, obstaculiza la organización del flujo de información, y la posible creación de indicadores de éxito y métricas comunes, capaces de generar un banco de datos fiable para la evaluación comparativa de diferentes alternativas de proyectos. De este modo, en el próximo apartado, se ha planteado un marco conceptual que abarca todas las posibles actividades requeridas en el proceso de promoción de centros comerciales tradicionales y su interrelación con la estrategia de negocio. El objetivo que se pretende con este marco es crear una organización sistémica capaz de dirigir de manera clara y sencilla el desarrollo de las actividades de promoción con un enfoque en la estrategia de negocio.

\section{Marco teórico: definición de etapas y actividades del proceso de promoción de centros comerciales}

El modelo propuesto, además de la reagrupación de las fases principales establecidas por Peiser y Halmilton, (2012) y Rocha lima (1996), propone una fase adicional considerada como la iniciación del proceso de promoción del centro comercial donde se define y especifica la estrategia de negocio, bajo los objetivos estratégicos establecidos por la empresa promotora. De este modo, el marco conceptual propuesto abarca cuatro fases principales (Figura 2): Definición de la estrategia de negocio, Predesarrollo, Desarrollo del negocio y Gestión del negocio. Dichas fases se dividen en otras subetapas definidas con la reorganización de las actividades y tareas significativas del proceso a fin de interrelacionarlas con la estrategia de la empresa promotora y crear un modelo sistémico.

Por ello, el marco teórico propuesto está estructurado en cuatro fases, ocho etapas principales y veintidós actividades fundamentales (Figura 2). Las etapas son secuenciales y las actividades son agrupadas de acuerdo momento del proceso de promoción inmobiliaria al que van vinculadas. La conformación de los componentes del marco propuesto está basada en el ciclo de vida del negocio que será detallado más adelante. 
Figura 2. Estructura del proceso de promoción de centros comerciales

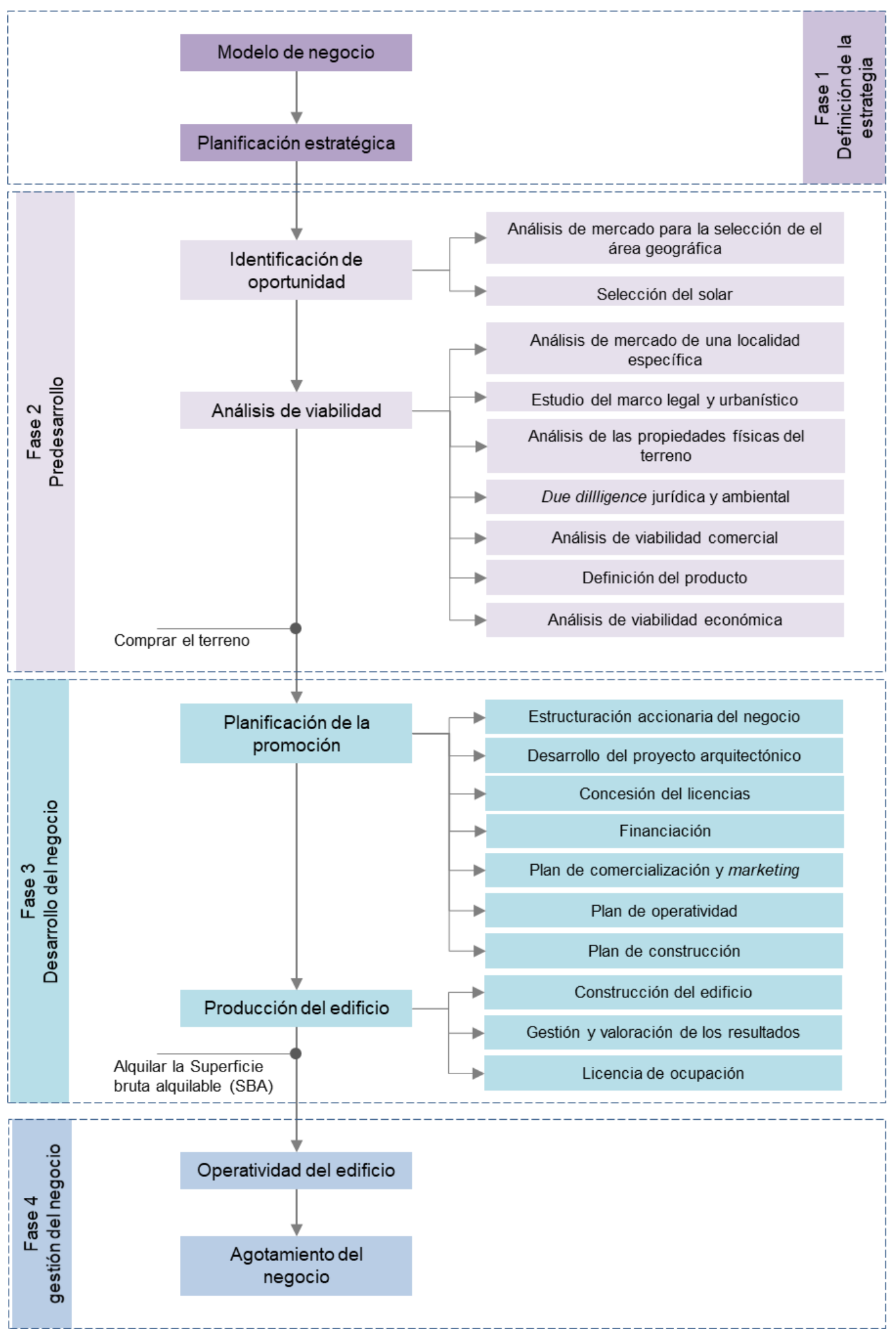

Fuente: Elaboración propia.

ACE, 14 (4.2) CC BY-ND 3.0 ES | UPC Barcelona, España | Marco teórico para la planificación estratégica y gestión del proceso 


\subsection{Fase 1 - definición de la estrategia de negocio}

La estrategia de negocio determina el éxito o el fracaso de una empresa promotora. De este modo, el modelo de negocio es la esencia de la estrategia elegida por la empresa (Gambardella y McGahan 2010; Casadesus-Masanell y Ricart 2010) y representa de manera lógica cómo opera y crea valor para sus accionistas (Chesbrough y Rosenbloom 2002; Osterwalder y Pigneur 2013; Teece 2010; Zott y Amit 2010).

Bajo esta perspectiva, los proyectos son los vehículos usados para la ejecución de las estrategias diseñadas por la empresa promotora, estando la gestión de proyectos y estrategia de negocio estrechamente entrelazados (Peiser y Halmilton, 2012). Por ello, el éxito de la estrategia se ve directamente determinado por la calidad del flujo de información o comunicación entre los diferentes niveles jerárquicos y la calidad de la ejecución del proyecto.

De esta manera, esta fase debe englobar los elementos que condicionan el desarrollo de la promoción de un edificio y detallar los mecanismos que conducen a la empresa hacia los objetivos trazados (Bueno, 2009). Dicha fase abarca dos etapas principales:

\section{Modelo de negocio}

El modelo de negocio traduce la estrategia en elementos interdependientes que guían a los gerentes a ajustar sus acciones para obtener la ventaja competitiva de la empresa. Dichos elementos abarcan cuatro áreas fundamentales de un negocio: estructura interna, propuesta de valor, mercado de actuación y estructura financiera, las cuales se dividen a su vez en nueve aspectos: asociaciones claves, actividades claves y recursos claves; propuesta de valor; segmento de mercado, relaciones con clientes, canales; estructura de costes e ingresos (Figura 3).

La interrelación entre dichos aspectos debe ser entendible de modo intuitivo ya que establecen cómo la estrategia será implementada a través de las estructuras de la organización, sus procesos y sistemas (Osterwalder y Pigneur, 2013). Asimismo, la adopción de una nueva estrategia implica el desarrollo de un nuevo modelo de negocio cuya estructura debe ser flexible para que dichos cambios puedan realizarse dentro de un marco estratégico ya existente de modo dinámico (Sorescu et al., 2011). Bajo esta perspectiva, la Figura 3 detalla dichos aspectos y los organiza de acuerdo con el lienzo de modelo de negocios desarrollada por Osterwalder y Pigneur (2013).

Puesto que, el centro comercial es un activo inmobiliario que tiene un carácter empresarial (Scott, 2018), dicha interrelación de las áreas fundamentales del modelo es importante para entender la gestión del activo, pues esta está determinada por la estrategia de la empresa. Además, el centro comercial tiene un fuerte carácter socioeconómico y cultural, de modo en que necesita estar en contacto directo con los consumidores. Esta relación suministra a los promotores claves para crear espacios adaptados a las necesidades de los consumidores y experiencias únicas a partir de innovaciones que lleven a cabo la propuesta de valor del centro comercial.

Cabe destacar que la coyuntura del sector de centros comerciales está fuertemente condicionada por los avances tecnológicos de transformación, crecimiento del e-commerce, y la dinámica del sector minorista. El éxito de un proyecto debe conectarse a las innovaciones que permitan al promotorn interactuar y comunicarse con los consumidores habituados a las tecnologías de compra, que exigen nuevas experiencias en un mundo de multicanales de compra. Por ello, el clásico modelo de negocio de centros comerciales ya resulta obsoleto (Kramer, 2008; ICSC, 2014; Brown y Lubelczyk, 2019). La función de los comercios físicos se transforma radicalmente, y las tiendas hoy en día están obligadas a plantear nuevas configuraciones y servicios que ofrezcan una experiencia completa y novedosa de la marca. de promoción de centros comerciales. DOI: http://dx.doi.org/10.5821/ace.14.42.8748 
Figura 3. Estructura del modelo de negocio y la definición de sus elementos

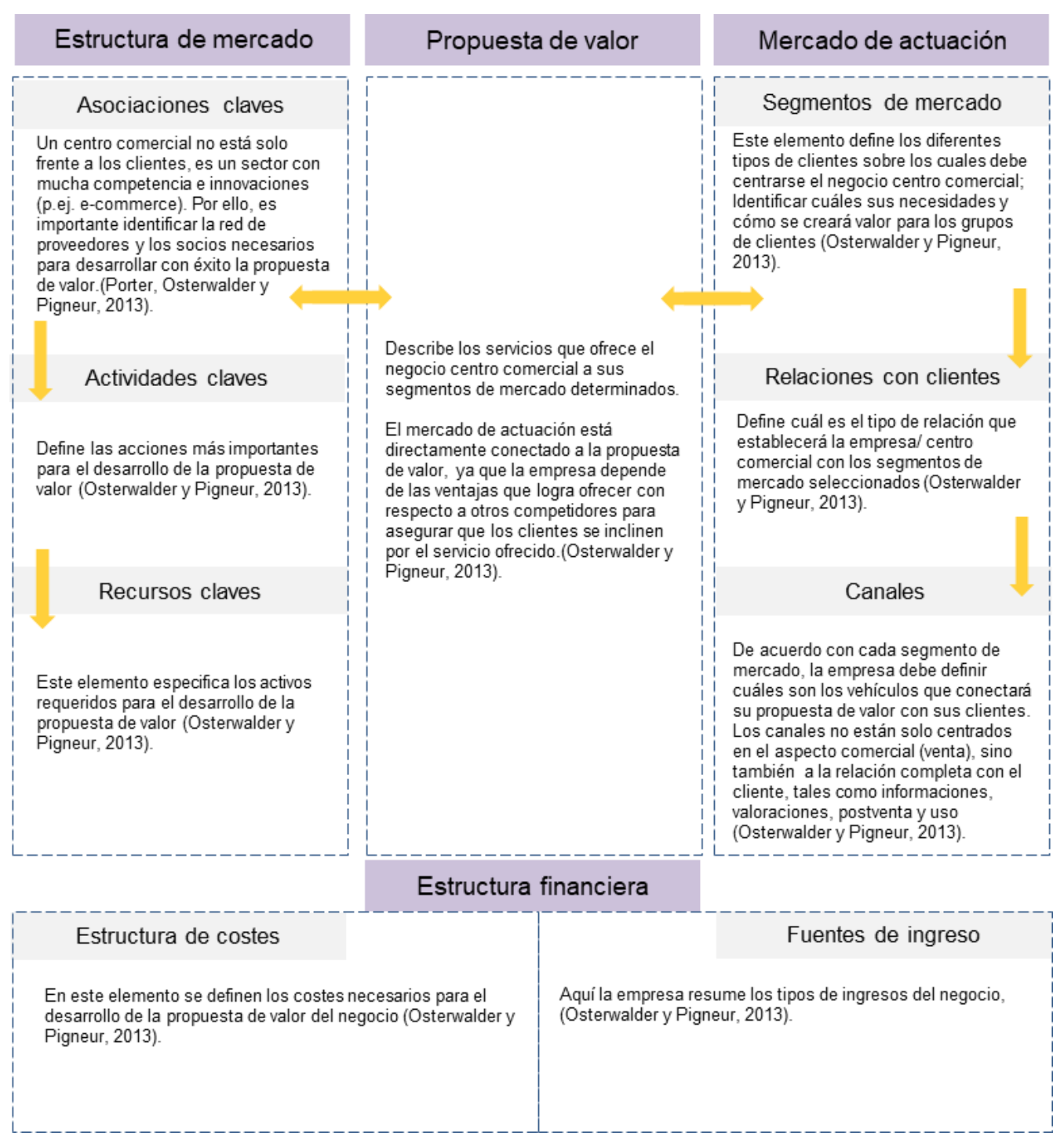

Fuente: Elaboración propia a partir del business model canvas, Osterwalder y Pigneur (2013).

En este sentido, el centro comercial debe crear espacios diferenciados que abarquen, no solo una amplia y variada mezcla comercial, sino también un conjunto atractivo de servicios (p.ej. spa, restaurantes, cines, teatros), que tiene por objetivo atraer a más consumidores y aumentar la posibilidad de comercialización de sus espacios. Por ello, muchos promotores utilizan la construcción de otros tipos de propiedades inmobiliarias (p.ej. oficinas, centro de ocio, hotel, residenciales), ubicados en varias estructuras conectadas al centro comercial tradicional, creando una sinergia para aumentar el flujo de consumidores a partir de nuevas experiencias y facilidades (Vernor, 2009; White et al., 1996). Con todos estos cambios, se deben analizar nuevas estrategias para direccionar a la empresa hacia la creación de servicios cada vez más innovadores, posicionamientos diferenciados e infraestructuras eficientes (Magretta, 2002; Kramer, 2008).

De este modo, aunque cada empresa tenga sus particularidades y cada centro comercial sea único (Kramer, 2008; Scott, 2018), existen aspectos fundamentales comunes, ya sea por su posición de mercado o por su potencial para crear valor (Kramer, 2008; Vernor, 2009; ICSC, 2014). Se deben de promoción de centros comerciales. DOI: http://dx.doi.org/10.5821/ace.14.42.8748 
considerar las transformaciones sociales, principalmente la creciente influencia de la generación milenium, el rápido avance de la tecnología, las preocupaciones ambientales y del comercio online que han creado nuevos desafíos y oportunidades para los propietarios de centros comerciales (ICSC, 2016). Se debe establecer tanto en proyectos de nuevos centros comerciales como en actuaciones de remodelación, como el nuevo centro comercial puede posicionarse frente a dichos cambios para garantizar el éxito en lo que probablemente sea un entorno empresarial radicalmente diferente al existente hace pocos años (ICSC, 2016; ICSC, 2019).

En la Figura 4 se sintetizan dichos aspectos claves, a través de la estructura de modelo de negocio especificado en la Figura 3. Es importante señalar que dichos aspectos deberán ser traducidos en la futura planificación estratégica del negocio centro comercial para que la estrategia sea claramente entendible en la gestión del proyecto.

Figura 4. Aspectos claves que deben ser considerados en el modelo de negocio centro comercial

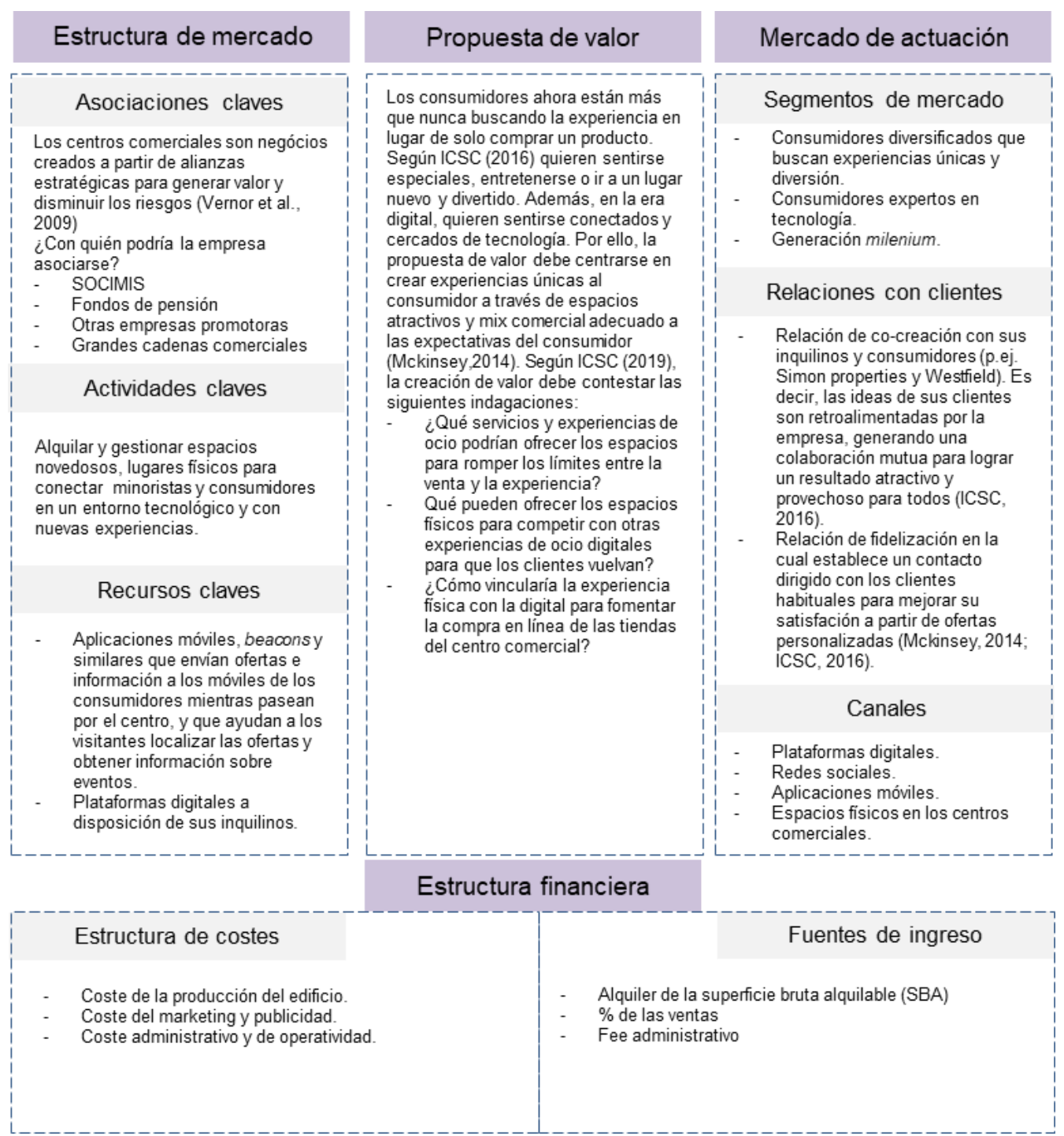

Fuente: Elaboración propia a partir del business model canvas, Osterwalder y Pigneur (2013).

ACE, 14 (42) CC BY-ND 3.0 ES | UPC Barcelona, España | Marco teórico para la planificación estratégica y gestión del proceso de promoción de centros comerciales. DOI: http://dx.doi.org/10.5821/ace.14.42.8748 


\section{La etapa de planificación estratégica del negocio}

Peiser y Halmilton (2012), señala que el plan estratégico es la clave que orienta a todo el equipo sobre cómo alcanzar los objetivos a nivel del negocio y proyecto. Este documento dirige la toma de decisiones en todos sus niveles jerárquicos. Es decir, traduce la dinámica de la filosofía corporativa, la cultura y las estrategias comerciales del modelo de negocio en la gestión del proyecto, proporcionando impulsores del proceso de toma de decisiones en las diversas etapas de la promoción inmobiliaria (Morris y Jamieson, 2004). Además, el proceso de planificación estratégica permite a los gerentes medir los logros del proyecto contra las expectativas proyectadas.

Por ello, un proceso con flujos de información mal estructurado genera una mala gestión de proyecto y de su operatividad. Tanto los objetivos y valores de la empresa como las acciones diseñadas para concretizarlos, deben conocerse por todo el equipo que participa en la definición del proyecto. Además, para la correcta planificación es importante considerar las particularidades de este activo inmobiliario que engloba características tanto del sector inmobiliario de carácter terciario como las características del mercado al por menor. De este modo, los objetivos estratégicos de posición de mercado están íntimamente vinculados a la imagen y a la cuota de mercado de las principales cadenas comerciales seleccionadas como tiendas motoras, ya que ocuparán la principal superficie bruta alquilable (SBA) del edificio a fin de hacer con que el centro comercial sea comercialmente viable y rentable.

Es importante considerar que el proyecto de promoción del edificio suele formar parte de una cartera de inversión de la empresa promotora/inversora. A su vez, la gestión de la cartera suele incorporar proyectos objetivos similares, centrándose en priorizar recursos y optimizar los beneficios de las inversiones. Por lo tanto, la gestión de cartera tiende a seleccionar y anteponer los proyectos más rentables para los inversores, mediante una visión conjunta de los diferentes componentes. Por ello, dicho proceso abarca objetivos multidimensionales que deben ser considerados en todas las etapas de promoción incluyendo la estabilización del activo y posterior remodelación o venta. De este modo, este enfoque establece tres etapas (Figura 5), que estructuran un documento para comunicar con el equipo los objetivos comerciales y las acciones para lograr dichos objetivos (Porter y Kramer, 2006; Kerzner, 2001).

1. Proceso de formulación: comprende la definición de los objetivos que respondan a la estrategia del nuevo negocio y pretendan conseguir la competitividad dentro del mercado. Se realiza mediante el desarrollo de valores de alta dirección que proporcionan un modelo de decisión decisivo (Kerzner, 2001). Hay tres temas que se deben formular:

- Análisis del entorno externo (p. ej., Tendencias del mercado, entorno político, comportamiento y riesgos de la competencia) en busca de condiciones susceptibles de cambio que identifiquen oportunidades o amenazas sostenibles.

- Análisis de los recursos de la empresa y la capacidad de gestión de las fortalezas y debilidades de los activos.

- Establecer los objetivos de proyecto para perseguir la estrategia comercial basada en los valores de la empresa y su sentido de responsabilidad con las intenciones de sus stakeholders.

2. Proceso de implementación: establece reglas y procedimientos para crear un ajuste entre los objetivos de la empresa y sus actividades en curso. Según Kerzner (2001), la gestión de la integración es una competencia central importante de la gestión del proyecto. Aquí, deben analizarse todas las posibles actividades para optimizar la creación de valor.

3. Proceso de identificación de la oportunidad: establece el proceso lógico de toma de decisiones que hace parte de la identificación y selección del nuevo proyecto. Las listas de verificación con los 
principales objetivos se pueden crear con los siguientes temas para ayudar a los directores y gerentes a simplificar el proceso de seguir o no seguir con el proyecto de inversión:

- $\quad$ El tamaño potencial del mercado y su posición en el mercado.

- La respuesta competitiva esperada.

- Los riesgos potenciales aceptables para el negocio.

- La estrategia para la selección y adquisición de terrenos para construir el centro comercial.

- Los requisitos de capital para el desarrollo del edificio.

- El grado de aceptación social.

- Oportunidades técnicas para la construcción del edificio.

- Capacidades de gestión de la cadena de suministro.

- Capacidades financieras.

Cabe señalar que estos criterios son una de las bases principales para la identificación y selección de oportunidades de negocios. Por lo tanto, la planificación estratégica crea la metodología para el proceso de selección del sitio, las negociaciones, la gestión del proyecto y la operatividad del edificio (Morris y Jamieson, 2004).

Figura 5. Las etapas de la estructuración de la planificación estratégica

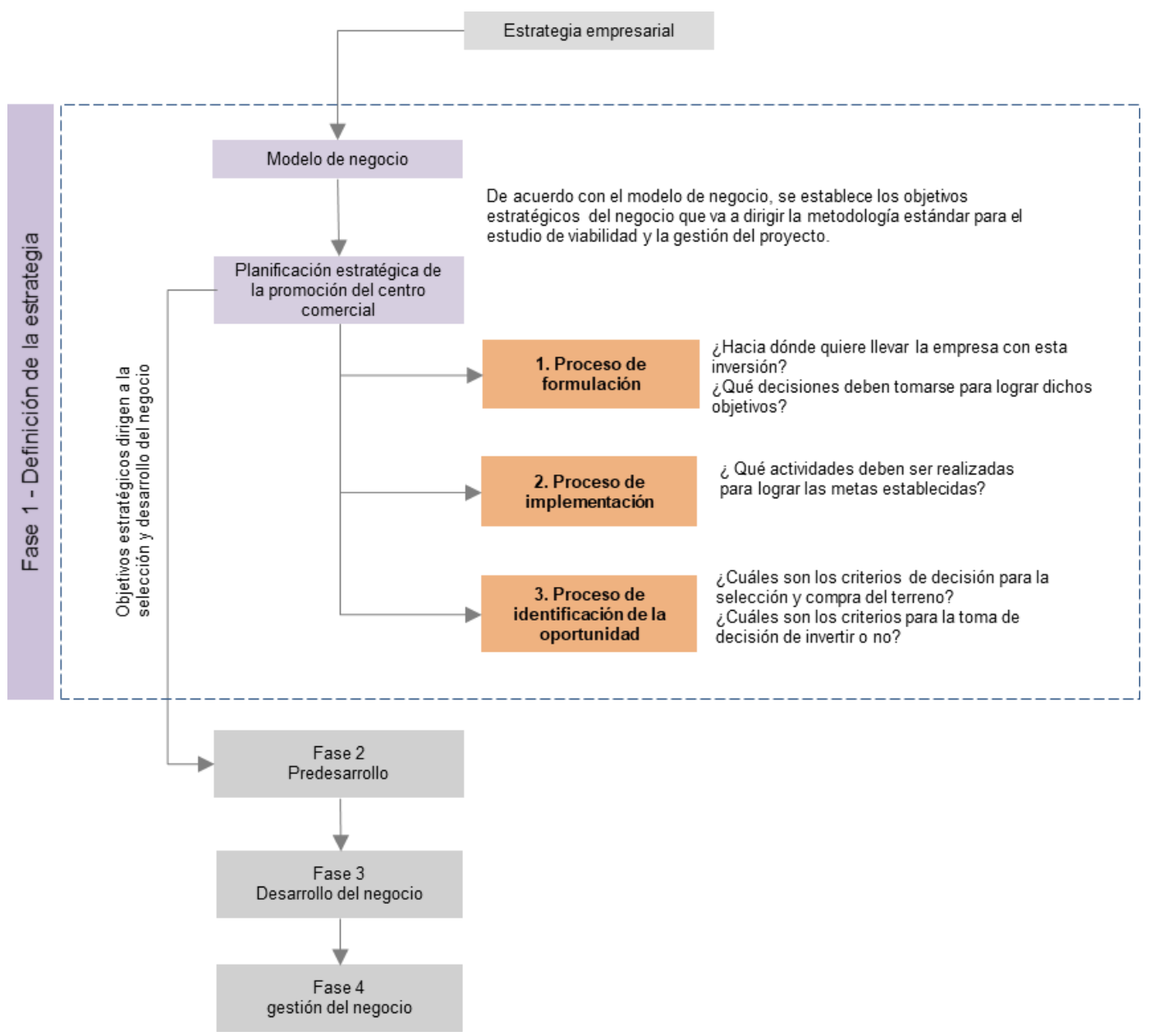

Fuente: Elaboración propia a partir Kerzer, 2001; Porter y Kramer, 2006

ACE, 14 (4.2) CC BY-ND 3.0 ES | UPC Barcelona, España | Marco teórico para la planificación estratégica y gestión del proceso de promoción de centros comerciales. DOI: http://dx.doi.org/10.5821/ace.14.42.8748 


\subsection{Fase 2 - Predesarrollo}

La fase de Predesarrollo del activo inmobiliario se centra en las etapas vinculadas a la búsqueda de oportunidad de promoción de un nuevo edificio y posterior evaluación de su viabilidad según los objetivos estratégicos establecidos en la planificación estratégica corporativa. En esta fase, se selecciona una localización concreta o solar para desarrollar el proyecto. Por tanto, se requieren todos aquellos datos vinculados a aspectos financieros, físicos y mercadológicos que influyan en la toma de decisión de invertir o no en el proyecto. Dentro de este contexto, la fase de predesarrollo abarca dos etapas principales:

\section{La etapa de identificación de oportunidad}

Identificar una oportunidad de promoción de un nuevo edificio supone analizar dos factores claves. El primero de ellos es la identificación de una ubicación que tenga las características urbanas y socioeconómicas favorables para el desarrollo del edificio y segundo, la selección de un solar con aspectos físicos propicios a la implantación del proyecto. Esta etapa implica dos actividades que se vinculan y pueden ser consideradas como estudios previos al análisis de viabilidad del proyecto:

a) Análisis de Mercado para la selección de la ubicación

El análisis de mercado define las zonas con potencial comercial de una zona a través de la evaluación de factores claves tales como: [1] La fuerza de la competencia (centros comerciales y tiendas a pie de calle existentes en el medio circundante), [2] la calidad de acceso a los centros comerciales competidores (por general expresada por tiempo y distancia), y [3] la existencia de barreras físicas, culturales y socioeconómicas que pueden afectar las zonas de influencia (Peiser y Halmilton., 2012). Por ello, a partir del geomarketing, dicho análisis define la caracterización socioeconómica, demográfica y áreas de influencia del ámbito. A su vez, detalla la tendencia del volumen de venta segmentado por tipo de bienes y servicios, así como las características principales de la competencia

Según Kramer (2008), el promotor debe asegurarse de que el mercado puede absorber la superficie comercial que se plantea desarrollar. Por lo tanto, el análisis también debe cuantitativamente justificar la promoción de un nuevo edificio, bien sea por el incremento de la población o por el incremento del poder de compra de los habitantes. Esta información ayuda a determinar cómo el proyecto podrá posicionarse en el mercado potencial y si el volumen de venta pronosticado es suficiente para justificar la inversión.

b) Selección del solar

La mejor ubicación para la implantación de un edificio es aquel que tenga una gran visibilidad y accesibilidad, así como tamaño, forma y topografía adecuados al edificio y su posible expansión (Kramer, 2008; Peiser y Halmilton, 2012). Además, Kramer (2008) destaca que la ausencia de alguno de estos factores posiblemente afectará negativamente a la viabilidad del negocio, generando impactos negativos en el entorno como atascos y degradación ambiental. Por ello, la selección del solar es un estudio previo de reconocimiento del sitio que implica el análisis empírico de algunos aspectos claves importantes para la toma de decisión de adquisición del terreno.

Cabe destacar que este análisis empírico es un estudio cualitativo de la propiedad y su entorno. El experto técnico, apoyándose en sistemas de información geográfica y visitas in situ al terreno, define características intrínsecas y extrínsecas del solar incorporadas como informaciones preliminares al estudio de viabilidad. Este análisis, junto con el estudio de mercado, es capaz de dirigir la toma de decisión del promotor de iniciar o no el proyecto en esta concreta localización. Estas informaciones

ACE, 14 (4.2) CC BY-ND 3.0 ES | UPC Barcelona, España | Marco teórico para la planificación estratégica y gestión del proceso 13 de promoción de centros comerciales. DOI: http://dx.doi.org/10.5821/ace.14.42.8748 
también son muy relevantes para definir el propio valor del terreno y, por tanto, determinantes en una posible negociación de la adquisición de la propiedad.

\section{La etapa de análisis de viabilidad del proyecto}

El análisis de viabilidad del proyecto tiene por objetivo principal valorar, cualitativa y cuantitativamente, las ventajas, desventajas y riesgos del proyecto, bajo parámetros temporales, tecnológicos, políticos, sociales y ambientales. Se lleva a cabo mediante una evaluación exhaustiva de aspectos claves que afectan directamente a la adquisición del terreno, a las características físicas y económicas del nuevo edificio y, consecuentemente, al éxito de la inversión. Por ello, es necesario un equipo multidisciplinar de expertos, que en algunos casos pertenecen a la propia empresa y, en otros casos, son consultores externos especializados. Esta etapa es un proceso interactivo que se plantea dividir en siete actividades secuenciadas que pueden superponerse:

a) Análisis de mercado de una ubicación específica

Tras la elección del solar, el estudio de mercado previo se complementa con datos que suponen una micro visión de la ubicación seleccionada. Por ello, se definen los ámbitos geográficos (o de influencia) circundantes al centro comercial con informaciones detalladas de las condiciones socioeconómicas, mercadológicas y culturales de cada una de ellas. Por lo general, las empresas promotoras de centros comerciales suelen usar herramientas de geomarketing para plasmar datos que definan cómo los consumidores se relacionan con los bienes y servicios ofrecidos por la competencia y con el centro comercial propuesto.

Tras ello, se procede al análisis de los espacios comerciales que se consideran competidores directos, centros comerciales del mismo tipo que ofrezcan similares bienes y servicios pensados para el centro comercial propuesto. Es esta fase se analizan todos los aspectos que pueden condicionar la rentabilidad del centro: localización, fecha de apertura, cuota de mercado, tipología, dimensión, mezcla comercial y cadenas de tiendas instaladas (en especial las tiendas locomotoras).

El análisis sociodemográfico abarca cada sector del área de influencia y las proyecciones de sus futuras características, incluyendo el estudio de la evolución demográfica, concentración, dispersión y flujos migratorios; características socioeconómicas (sexo, pirámide de población, actividad profesional, sector de actividad, y tazas de motorización), nivel de renta (estimado por medio de indicadores de renta media y renta media disponible per cápita) y pauta de consumo (Kramer, 2008).

Dichos datos son utilizados para calcular la cuota de mercado esperada del centro comercial, en la que se identifica, en un posible escenario, la proporción de consumidores que elegirán los productos ofrecidos por el centro. Es decir, este análisis determinará las ventas potenciales del centro comercial. Esta metodología empírica, parte de la suposición de que un centro comercial de adecuadas características comerciales captará una parte del mercado donde se ubique. Por tanto, la caracterización del área de influencia es la base para determinar la cuota de atracción del centro comercial para cada uno de los sectores de influencia. Este análisis tiene por objetivo valorar la parte de ventas totales proyectadas para el área geográfica que será absorbida por el nuevo centro comercial.

b) Estudio del marco legal y urbanístico

Esta etapa tiene por objetivo conocer las directrices de carácter legal y urbanístico que definen la capacidad de desarrollo del suelo seleccionado. Esta actividad examina el modelo de ocupación, utilización y preservación del suelo, así como los elementos fundamentales de la estructura urbana y territorial del terreno elegido. El responsable técnico de esta etapa explora el plan de ordenación de promoción de centros comerciales. DOI: http://dx.doi.org/10.5821/ace.14.42.8748 
territorial y normativa urbanística del municipio con el objetivo de determinar la clasificación y calificación del suelo, definiendo los usos permitidos, la edificabilidad máxima, la altura máxima prevista, el fondo edificable permitido, así como los demás aspectos físicos admitidos en el terreno que delimiten la posibilidad de construcción del centro comercial planteado. Cabe destacar que esta etapa se define la materialización del aprovechamiento lucrativo del suelo, factor clave que se relaciona de forma directa con en el valor inmobiliario del terreno.

Otro punto importante es el análisis de la legislación aplicable en materia de protección ambiental y posible impacto de la implantación del edificio en el medio. Los centros comerciales son estructuras de gran escala que modifican de forma clara su entorno y requieren a menudo, para la concesión de las correspondientes licencias de edificación y actividad, medidas preventivas, correctoras o compensatorias adecuadas a la protección del medio ambiente. La ausencia de estas informaciones, en el estudio de viabilidad económico financiero, pueden causar impactos negativos en la rentabilidad del centro comercial, ya que son medidas de considerable valor para la inversión.

Además, en lo referente a las informaciones que proceden de esta etapa, los datos vinculados al desarrollo del estudio de viabilidad económico financiero, aclaraciones sobre los aspectos temporales, la documentación y los planes necesarios para la concesión de licencias de obras y uso, son fundamentales a fin de definir el análisis de riesgo, rentabilidad y la gestión futura del proyecto.

Cabe destacar que a menudo los centros comerciales requieren un soporte cuyas proporciones son difíciles de encontrarse en el suelo urbano consolidado. Por ello, muchas veces los nuevos centros comerciales son construidos en nuevos desarrollos donde la promoción de las parcelas a veces es realizada por una joint venture con la empresa promotora del centro comercial. Bajo este escenario, es fundamental que se conozca el tiempo de gestión de los instrumentos urbanísticos necesarios, ya que el tiempo de planificación e implantación del centro comercial depende de estos aspectos.

Es relevante evaluar en esta fase de pre-desarrollo, la viabilidad y tiempos previstos para la concesión de las correspondientes licencias urbanísticas, mediante las cuales la Administración realiza un control reglado de legalidad sobre las obras a desarrollar, usos propuestos o acto de transformación urbanística solicitado por el promotor. Hacemos referencia a licencias de obras de edificación, construcción e implantación de instalaciones de nueva planta, licencias de posible demolición, modificación o reforma de los edificios existentes o licencias de intervención sobre edificios, inmuebles y ámbitos patrimonialmente protegidos o catalogados, u otros permisos necesarios para ejecución de la actuación planteada.

Cabe señalar que en esta fase se dan lugar dos acciones estratégicas en el estudio de viabilidad de la inversión en el momento de la toma de decisión de adquisición del terreno potencial. En primer lugar, el levantamiento topográfico evidencia si la configuración y delimitación perimetral del terreno es acorde a la descripción registral recogida en los diferentes títulos de propiedad (analizadas en la correspondiente diligencia jurídica). En segundo lugar, el estudio geotécnico y geológico, establece la naturaleza y cualidad del suelo, que permite definir el tipo de cimentación, posibilidad de actuación bajo rasante e impacto en los costes de ejecución. Además, estas características influyen directamente en el posible volumen edificado, sobre y bajo rasante, y por tanto en el valor de mercado del terreno, por lo que debe conocerse previamente a la negociación de la adquisición de la propiedad.

c) Diligencia debida (Due diligence) jurídica y ambiental

transacción de adquisición de una nueva propiedad en el ámbito empresarial, suele ir precedida por una diligencia adecuada (Due diligence), tanto de carácter jurídico como ambiental. Una Due dilligence jurídica y ambiental consiste en un análisis exhaustivo de todos los documentos significativos

ACE, 14 (42) CC BY-ND 3.0 ES | UPC Barcelona, España | Marco teórico para la planificación estratégica y gestión del proceso 15 de promoción de centros comerciales. DOI: http://dx.doi.org/10.5821/ace.14.42.8748 
vinculados al inmueble a fin de que el potencial comprador pueda confirmar que no existen "defectos ocultos" en el negocio. Para los promotores inmobiliarios, este análisis contribuye a la toma de decisión de adquisición del terreno basándose en informaciones fiables relativas a la situación física, jurídica y fiscal, así como la ética del actual propietario.

En lo referente a los contenidos específicos de una Due diligence, suelen cambiar según el tipo de propiedad, transacción y comprador. Sin embargo, en la mayoría de los casos la investigación plantea el análisis exhaustivo de los aspectos ambientales y jurídicos de la propiedad. Un consultor ambiental incorporará a su estudio parámetros que permitan establecer si existe contaminación del suelo o de las aguas freáticas asociadas. Este estudio evita que los promotores adquieran terrenos con problemáticas, difícilmente solucionables, y con un gasto elevado de recuperación para el fin propuesto

A su vez, el análisis jurídico tiene por objetivo evaluar las implicaciones legales vinculadas a la transacción inmobiliaria, analizando su situación registral, régimen de propiedad del bien, cargas y gravámenes, conduciendo las acciones necesarias para que la adquisición se lleve a cabo con total seguridad jurídica. Es decir, el asesor jurídico del promotor analiza cuidadosamente si constan cargas sobre el inmueble en el Registro de la Propiedad que, graven al activo, si existe limitación jurídica al hecho de compraventa del bien y si el pago de tributos y tasas que gravan directamente el inmueble están corrientes de pago.

Por último, las informaciones obtenidas en la diligencia debida están ligadas directamente a la toma de decisión de adquisición del terreno pues influyen directamente sobre la negociación de la transacción y el valor de la propiedad. Problemas ambientales suelen depreciar el valor del terreno, así como irregularidades jurídicas y fiscales pueden ser factores definitivos para la renuncia de adquisición del inmueble.

d) Análisis de viabilidad comercial

La promoción de un centro comercial es una co-venture entre promotores y las grandes cadenas comerciales, que son los elementos locomotores del negocio (Vernor, 2009; Kyriazis y Cloete, 2018). Por ello, las estrategias de promoción implican la vinculación de una serie de decisiones comerciales, financieras y formales. Estas medidas deben planificarse antes de la toma de decisión de inversión para crear escenarios potenciales de éxito, medir los riesgos de comercialización y definir las actividades a implantar en los locales más atractivos para el mercado objetivo.

Bajo esta perspectiva, en primer lugar, se identifica la composición óptima del edificio (mezcla comercial) según los parámetros de mercado analizados en el área de influencia (preferencias de los consumidores, mercado objetivo, bienes y servicios demandados, competencia y ritmo de crecimiento del área), destacando la importancia de las cadenas locomotoras del centro debido a su capacidad en generar un considerable flujo de consumidores por los espacios comerciales.

Por ello, el equipo comercial centrará sus esfuerzos en la captación del interés de las grandes marcas, que luego colaborarán con la viabilidad del negocio a partir del uso de su imagen para atraer los pequeños minoristas a la composición del centro comercial (Shanmugam, 2013). Debido a su importancia en la planificación del negocio, este tipo de inquilino suele tener valores de alquiler más bajos que la demás superficie bruta alquilable del centro comercial (SBA). Además, de acuerdo con el tipo de negociación, el centro comercial puede asumir el coste de la construcción de los espacios de estas tiendas u otros costes relacionados su implantación.

Según Vernor (2009), esto es debido a los grandes gastos de marketing que estas tiendas soportan con el objetivo de generar tráfico de consumidores en espacios comerciales no consolidados. La de promoción de centros comerciales. DOI: http://dx.doi.org/10.5821/ace.14.42.8748 
tienda "locomotora" pasa a ser un tipo de socio estratégico del negocio y la comercialización de los demás espacios rentables sólo empieza después de que el centro comercial tenga la seguridad de esta asociación. De este modo, las tiendas "locomotoras" son fundamentales no solo para determinar la ubicación del edificio en el terreno, el "layout" interno del edificio, sino también para la negociación financiera del alquiler de la SBA no ocupada por ellas. Dicha etapa de pre comercialización es un elemento clave para la obtención de posibles líneas de financiación y, por tanto, para el desarrollo del proyecto.

Las tiendas locomotoras, no solo son determinantes a la hora de definir la tipología e imagen del centro comercial, sino además influyen en la ubicación de los accesos, los costes de promoción, el plan de marketing y los costes operacionales del edificio (Kramer, 2008). Por ello, la mezcla comercial planteada debe proporcionar una interacción equilibrada entre todos los bienes y servicios ofrecidos por las tiendas, así como abarcar las principales cadenas de comercio del ámbito de influencia. El éxito de ventas del nuevo edificio estará determinado por la selección y la combinación de un grupo de tiendas complementarias que tienen por objetivo crear una oferta de bienes atractiva para suplir las necesidades del mercado objetivo seleccionado (Krame, 2008; Peiser y Halmilton, 2012).

El equipo comercial debe examinar los parámetros económicos y financieros del mercado minorista del área geográfica a fin de no realizar estimaciones incorrectas del ritmo de arrendamiento de los espacios y los ingresos derivados de estos. Es decir, el éxito de un edificio no está directa y exclusivamente vinculado a un atractivo valor de renta de la SBA y a las ventas de los bienes ofrecidos por el mix comercial, sino también a la capacidad de las tiendas inquilinas para soportar los costes operacionales y de marketing, así como de absorber incrementos en los gastos futuros.

e) Definición del producto

La definición del producto va estrechamente vinculada a la conceptualización del edificio en aspectos claves del análisis de viabilidad económico financiero del proyecto. De este modo, el programa comercial refleja el posicionamiento estratégico del promotor en el mercado al incorporar su perfil de riesgo y restricciones de capital para inversión. El proceso de definición del programa comercial es endógeno e interactivo, lo que hace que la matriz metodológica adoptada en la promoción del edificio sea distinta de la adoptada en la mayoría de los demás tipos de activos inmobiliarios (Kramer, 2008; Vernor 2009; ICSC, 2014).

Cabe señalar que el programa comercial suele ser dinámico, precisando revisiones periódicas tras la puesta en marcha del centro comercial y consolidación del mismo. La conceptualización del edificio es un proceso de comunicación interactiva donde el promotor equilibra potencias de mercado con los conceptos de desarrollo y ámbito potencial.

Tras ello, el diseño conceptual arquitectónico es la representación visual de las características y los aspectos definidos en el programa comercial. El enfoque clave del diseño conceptual es evaluar, desde el punto de vista técnico, si los parámetros establecidos para el nuevo edificio (SBA, tipología, número de plazas de aparcamiento, mezcla comercial y aspectos arquitectónicos) pueden desarrollarse al solar potencial elegido.

Cabe destacar que el diseño conceptual no detalla completamente el proyecto, pero si establece aspectos claves para el análisis de viabilidad, tales como el área y volumetría, la forma, programa funcional, sistemas constructivos, accesibilidad y el número de plazas de vehículos del edificio. En este momento, se definen aquellos parámetros arquitectónicos necesarios para valorar la viabilidad de la promoción en términos de tiempo, costes de construcción, calidad y rendimiento. La definición del producto y el diseño conceptual del edificio proporcionan datos clave en la inversión.

ACE, 14 (4.2) CC BY-ND 3.0 ES | UPC Barcelona, España | Marco teórico para la planificación estratégica y gestión del proceso de promoción de centros comerciales. DOI: http://dx.doi.org/10.5821/ace.14.42.8748 
El principal objetivo del estudio de viabilidad económico-financiero es valorar la rentabilidad del proyecto potencial. Este análisis evalúa si el nuevo edificio conceptualizado es capaz de generar suficientes ingresos para cubrir los costes de inversión, así como producir el retorno esperado por los inversores. Estos aspectos son los principales factores que afectan a la toma de decisión de cada etapa del proceso, desde la adquisición del terreno, tipo de financiación hasta la operatividad del edificio.

Por tanto, el inversor va a medir el impacto de su decisión de inversión, a través de indicadores de rentabilidad de carácter económico-financiero. Aunque en múltiples ocasiones se utilizan modelos económicos genéricos a activos inmobiliarios que se posicionan en el mercado en rentabilidad, cabe señalar que los centros comerciales presentan aspectos diferenciales que deben ser incorporados. Se trata de un mercado muy específico donde la rentabilidad del edificio depende directamente del flujo de ventas de las tiendas, ciclos de mercado, estructura de riesgo específica, futuras expectativas de retorno de la inversión y coste de oportunidad de las cadenas de comercio inquilinas, así como a los aspectos temporales del mercado minorista.

\subsection{Fase 3 - Desarrollo del negocio}

La fase de desarrollo del negocio abarca las actividades de planificación e implantación del proyecto. En esta fase se dan lugar los mayores riesgos que pueden impactar en el rendimiento de la inversión. Desviaciones en los plazos y previsiones económicas pueden impactar negativamente el rendimiento de la inversión, y posterior operatividad y mantenimiento del edificio. La fase de desarrollo del negocio abarca dos etapas principales que implican actividades claves para la implementación de un proyecto de promoción inmobiliaria: la planificación del proyecto y la producción del edificio., financiero y constructivo

\section{Planificación del proyecto del centro comercial}

Tras la toma de decisión de invertir en el edificio conceptualizado, la planificación de la promoción implica una serie de actividades que tienen por objetivo desarrollar, organizar y gestionar el proyecto arquitectónico, la construcción, la gestión de la operatividad y mantenimiento del edificio. A partir de datos concretos, se desarrolla la planificación financiera de la inversión, la obtención de licencias y permisos, así como los contratos profesionales necesarios para la construcción del edificio (empresa constructora y gestora de proyectos).

De este modo, el negocio abarcará principios fundamentales de gestión de proyectos que están centrados no sólo en la calidad del proyecto arquitectónico, sino también en el éxito de la inversión. Cabe destacar que dichos principios, engloban el balance de restricciones de gestión como: alcance, calidad, tiempo, recursos y riesgos del proyecto (PMBOK, 2011). La relación de tales factores ocurre de tal manera, que si alguno de ellos cambia otro factor se verá afectado. Este potencial de cambio, justifica la necesidad de una planificación detallada que comienza con el estudio de viabilidad y se extiende hasta la consolidación del negocio, ya que dichos factores impactan directamente en el rendimiento final del negocio (Brioso, 2015).

Por ello, aunque el plan de gestión del proyecto sea interactivo y evolucione progresivamente, los resultados parciales que se van obteniendo no pueden desviarse negativamente de los datos iniciales. De este modo, el resultado final del negocio no será negativo en relación al resultado preestablecido que guió la toma de decisión de invertir. Bajo este contexto, se debe pormenorizar los datos claves del proyecto arquitectónico que interferirán en los costes finales de la inversión.

ACE, 14 (4.2) CC BY-ND 3.0 ES | UPC Barcelona, España | Marco teórico para la planificación estratégica y gestión del proceso 18 de promoción de centros comerciales. DOI: http://dx.doi.org/10.5821/ace.14.42.8748 
La planificación del desarrollo del proyecto arquitectónico deberá reconocer tanto la importancia de la superficie bruta alquilable (SBA) como la necesidad de confort y facilidad de operatividad, accesos y mantenimiento del edificio. De este modo, los profesionales implicados en esta actividad tienen que unir en su toma de decisiones aspectos proyectuales y de negocio.

En este sentido, el edificio debe presentar una alta funcionalidad y flexibilidad, nivel óptimo en la automatización de las instalaciones e integración de los servicios, bajo impacto ambiental y calificación de eficiencia energética adecuado, entando en línea con las normativas técnicas de aplicación, así como propiciar un bajo coste operativo, auto rendimiento y larga vida útil. Además, el proyecto tendrá que estar en línea con el plan de comercialización. El diseño arquitectónico, acabados y decoración no puede comprometer el coste de mantenimiento de los espacios, la funcionalidad necesitada por el equipo de operatividad, y tampoco dificultar la flexibilidad requerida para dar respuesta al plan de comercialización propuesto para el centro comercial.

De este modo, se hace necesario incorporar en la etapa de planificación, cuestiones relacionadas con la posible expansión futura del centro comercial, así como su remodelación o desmantelamiento del negocio debido a su agotamiento. Esta acción permitirá evitar pérdidas de recursos tanto materiales, financieros, humanos o temporales. Para ello, en esta etapa se deben especificar las futuras opciones de desarrollo o ampliaciones y hacerlas compatibles con las soluciones iniciales.

\section{Producción del edificio}

La producción o construcción del edificio abarca numerosas variables, que podrían agruparse en dos grandes campos: gestión de ejecución y gestión económica de la obra. El objetivo principal de esta fase es controlar las acciones de la empresa constructora para que la construcción del centro comercial se realice bajo el empleo de buenas prácticas y dentro del presupuesto establecido.

La empresa promotora debe aclarar todas las acciones que deben ser cumplidas por la empresa constructora, recogiéndose las correspondientes cláusulas en el contrato de obra, siempre acordes al correspondiente Pliego de Condiciones del Proyecto de Edificación y al Estudio de Seguridad. A su vez estas acciones estarán relacionadas con cuestiones de derechos y seguridad de los empleados, sistema de gestión ambiental de la construcción (SGA) de acuerdo con la ISO 14001, gestión de calidad ISO 9001, así como las prácticas de RSE por parte de todos los proveedores de la construcción (Vernor, 2009; Vieira de castro y Ramírez, 2017). En este sentido, el equipo técnico de la empresa promotora detalla los límites máximos aceptables, en los diferentes ámbitos, para cada obra y que deberán ser asumidos por la empresa contratada.

Cabe destacar que los aspectos anteriormente indicados están ligados directamente con los costes de la construcción. Por ello se debe realizar una gestión de riesgos durante la vida del proyecto con el objeto de minimizar fallos vinculados a aspectos como la organización del área de trabajo, los accidentes por falta del cumplimiento de normativas, la ausencia de un orden en la disposición de equipos, materiales y gestión de los residuos, así como los escases de informaciones en el plan de ejecución de la construcción.

Por ello, se hace necesario efectuar una guía que asegure la calidad de producción, haciendo especial hincapié en el orden, organización, seguridad, protección del medio natural y gestión de los recursos (materiales, humanos y temporales). De este modo, se permite elevar el rendimiento del negocio, además de aportar un producto final de alta calidad y de bajo impacto ambiental, económico y social. 


\subsection{Fase 4 - Gestión del centro comercial}

Esta fase comienza con la ocupación del edificio, continúa con la puesta en funcionamiento del centro, la remodelación de sus espacios o cambios de uso y finaliza con el desmantelamiento del centro comercial. Es una fase administrativa que abarca etapas claves, la operación y mantenimiento del edificio y posterior agotamiento del negocio, que tienen por objetivo mantener la rentabilidad de la inversión o incrementarla (Kramer, 2008; Berman y Evans, 2001).

De modo general, el periodo de gestión se interconecta con el ciclo de vida de posicionamiento en el mercado del negocio (innovación, crecimiento, madurez y declive) como se puede observar en la Figura 6. Esta fase está vinculada de forma directa con factores de mercado, estrategias del promotor y estrategias de los minoristas, tal y como se indica en la imagen 6 (Lowry, 1997; Berman y Evans, 2001; Abrudan y Dabija, 2009).

Una vez que empieza la operación del centro comercial (etapa de innovación), su vacancia es muy baja y las ventas son estimuladas por la intensa publicidad que genera un gran flujo de compradores también estimulados por las nuevas experiencias existentes en el centro comercial. Por ello, se incrementa rápidamente los ingresos y el valor de sus espacios alquilables. Dicho flujo continúa aumentando constantemente estimulado por la estrategia de marketing del centro comercial en conjunto con las tiendas locomotoras (Lowry, 1997; Abrudan y Dabija, 2009; Kusumowidagdo et al., 2011).

De este modo, la rentabilidad del centro comercial sigue el crecimiento (etapa de crecimiento) y las actividades promocionales pasan a centrarse en momentos claves del año para el comercio minorista (p.ej. navidad, día de la madre, pascua). Aunque la tasa de vacante tenga un porcentaje pequeño y moderado, los espacios rentables ya necesitan de pequeños reparos y son ajustados a las nuevas demandas (Lowry, 1997; Abrudan y Dabija, 2009; Kusumowidagdo et al., 2011). En el ciclo de madurez, sin presentar innovaciones de los espacios el tráfico de clientes y ventas se estabiliza, incluso a veces se ralentiza debido a la competencia, tanto de otros centros físicos como de comercio online (Kramer, 2008; Kusumowidagdo et al., 2011). Uno de los objetivos estratégicos de la fase de gestión es impulsar los esfuerzos en publicidad y técnicas de marketing para mantener su posición de mercado.

Finalmente, el activo sufre un agotamiento, ya sea por las nuevas exigencias del público o por la necesidad de expansión de sus áreas. El centro comercial se encuentra en una condición debilitada, el flujo de compradores suele ser bajo y el crecimiento de las ventas es negativo, lo que exige grandes esfuerzos del centro comercial para mantener a sus inquilinos y visitantes. Este momento es la etapa de agotamiento del negocio, en el que se analizan las necesidades de remodelación global del edificio o su venta, de acuerdo con la estrategia del promotor (Lowry, 1997; Abrudan y Dabija, 2009; Kusumowidagdo et al., 2011).

Bajo esta perspectiva, la gestión del centro comercial es un factor clave para el éxito de los centros comerciales, y no solo abarca actividades de mantenimiento y operatividad de la estructura del centro comercial, sino también de gestión de la imagen del centro y la rentabilidad de la inversión. Según ICSC (2014), en Europa las funciones de gestión de esta etapa están divididas en dos áreas: gestión responsable del activo como componente de la cartera del inversor y administración del propio centro comercial. Por lo tanto, las decisiones se toman, en distintos niveles jerárquicos del negocio inmobiliario (organización-cartera-edificio), y los objetivos estratégicos de cada nivel interactúan e influyen directamente en la rentabilidad del activo y de la cartera de la empresa promotora. 
Figura 6. Relación entre el ciclo de vida del mercado y las etapas de gestión del centro comercial

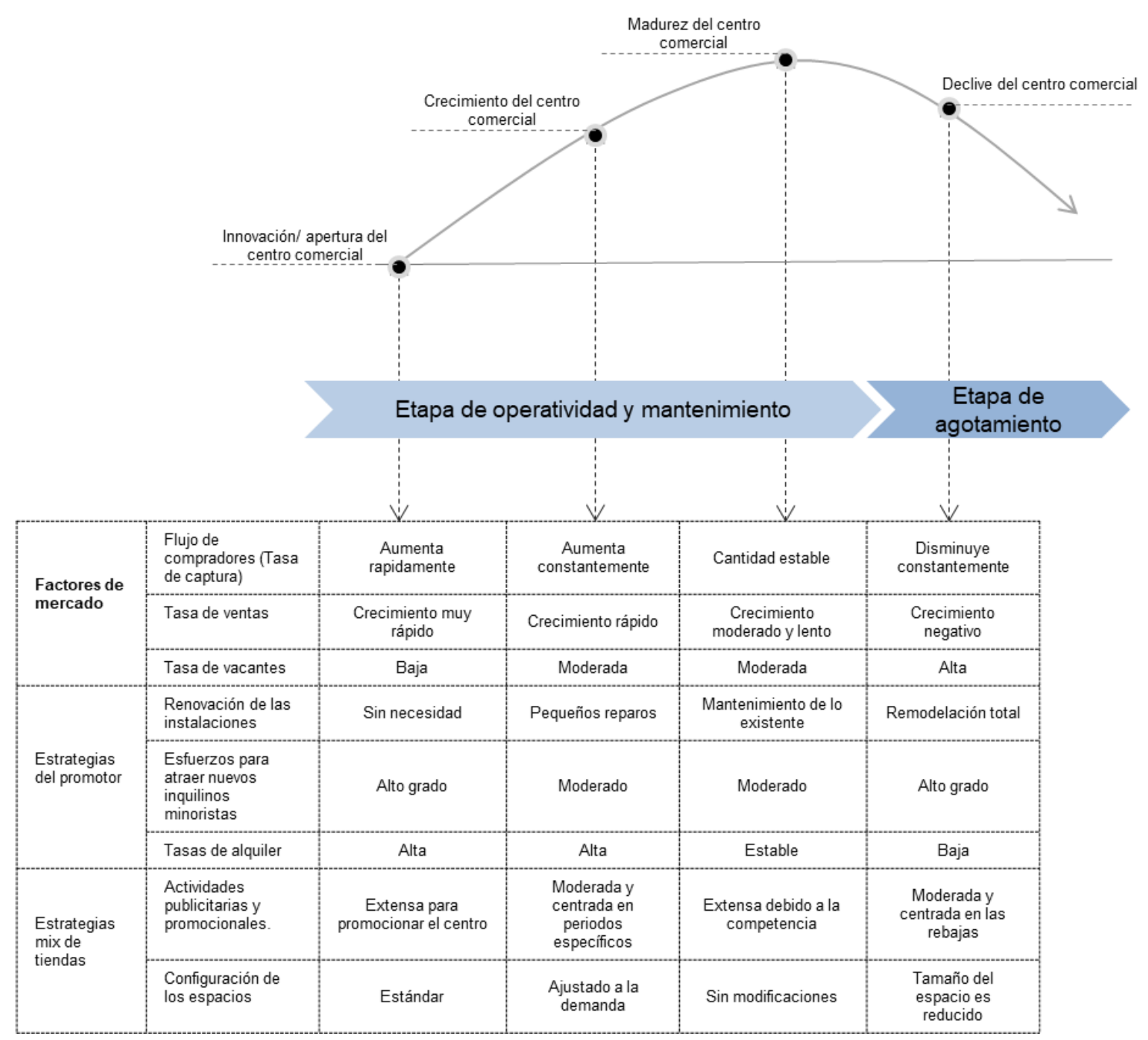

Fuente: Elaboración propia a partir de Abrudan y Dabija (2009) y Kusumowidagdo et al. (2011).

\section{Etapa de operatividad y mantenimiento del edificio}

El plan de operatividad del edificio depende de características propias de la promoción, tales como el modelo de gestión de la empresa promotora, la estructura de propiedad y la configuración del activo. En términos generales, la administración del centro comercial incluye cuatro funciones, que impactan directamente la viabilidad del negocio: Facility management, Marketing, Gestión administrativa y Gestión financiera y Comunicación de resultados. Por ello, los profesionales implicados en la valoración del negocio y gestión deben saber cómo los costes operacionales y los ingresos interactúan en el análisis de inversión y en la futura operatividad y mantenimiento del edificio (Vieira de Castro y Ramírez, 2017).

El conocimiento exhaustivo de estas características evitará impactos negativos en la rentabilidad del activo. A continuación (Figura 7) se indica que funciones se gestionan por el área de gestión del bien inmueble y cuáles por el área de gestión de la cartera de inversión, así como sus relaciones con el resultado financiero. 
Figura 7. Los sectores de gestión de la operatividad y mantenimiento del centro comercial y su relación con las áreas de gestión

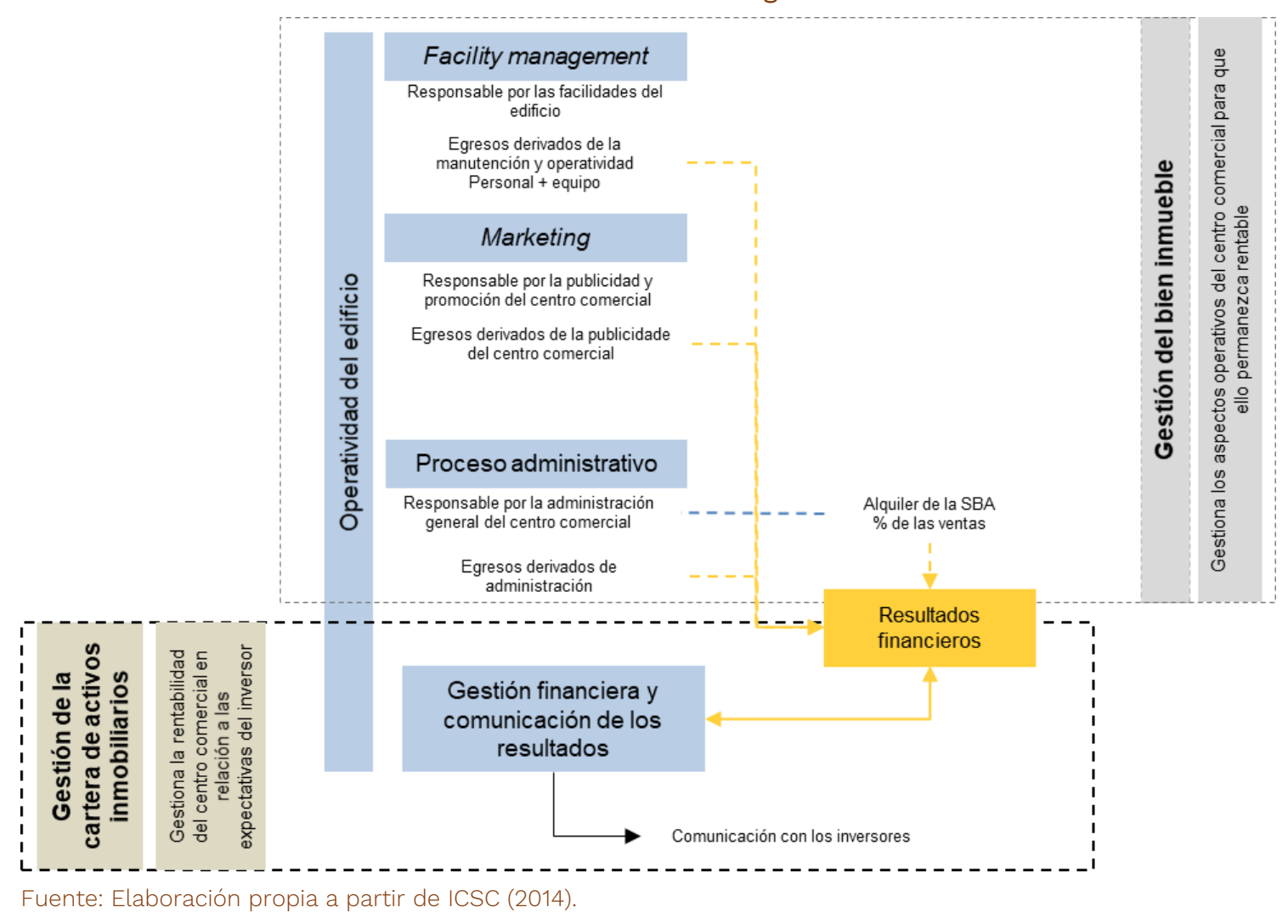

a) Facility management - Es la gestión de los procesos de operatividad de las instalaciones, espacios, personal y tecnología del edificio que van desde la accesibilidad, aparcamiento, seguridad, limpieza y servicios electromecánicos como supresión y detección de incendios, control de acceso, gestión de energía, fontanería de gestión de agua, cadena de suministro, logística y diseño (ICSC, 2014). Esta fase también integra la gestión de las obras de reforma y mantenimiento necesarias para que el centro se mantenga su competitividad en las etapas de crecimiento y madurez (Alexander y Muhlebach, 2019).

b) Marketing y publicidad - Los eventos promocionales ayudan a promover el mix de tiendas y son una parte esencial de la gestión del centro comercial. Algunos de los modelos promocionales más efectivos incluyen festivales, programas y celebraciones culturales que aumentan el flujo de clientes y, como resultado, aumentan los ingresos. Su planificación y puesta en marcha es analizada por el área de gestión del bien inmueble (property manager), en línea a la planificación estratégica del promotor y el presupuesto de marketing existente (ICSC, 2014; Alexander y Muhlebach, 2019).

c) Gestión administrativa - Llevada a cabo por la administración general del centro comercial verifica la correcta operación del centro comercial bajo la planificación estratégica del promotor. Consiste en gestión de la facturación, financiación, contabilidad, nóminas, recursos humanos. Es resumen, la gestión de todos aquellos aspectos que se deben tener en cuenta para garantizar un flujo de caja positivo del centro comercial y su mantenimiento seguro en el mercado. Asimismo, se ocupa de la gestión de los contratos de alquiler, la relación con los minoristas y la configuración del mix de tiendas de acuerdo con la demanda (ISCS, 2014; Kyriazis y Cloete, 2018; Alexander y Muhlebach, 2019). 
d) Gestión financiera y comunicación de los resultados - Llevada a cabo por el gestor de la cartera de activos inmobiliarios del inversor (Asset Manager). La gestión financiera incluye una serie de actuaciones que permitan el control de la inversión. Incluye la definición de indicadores financieros fiables tales como NOI (Net Operating Income), Operational expenditures (OPEX) y YIELD, que permiten comparar el resultado del activo con los demás integrantes de la cartera de la empresa. Además, cubre el proceso de identificación y gestión de riesgos, así como los informes para los posibles inversores (Alexander y Muhlebach, 2019).

\section{Etapa de agotamiento}

Cuando el centro comercial se torna obsoleto, se hace necesario una remodelación por completo de sus espacios, servicios y SBA para incorporar tecnología a su configuración (ICSC, 2016). En este momento, el promotor planifica el reposicionamiento del centro comercial de acuerdo con la demanda del mercado que el actual centro comercial no logra atender. Por ello, en primer lugar, se debe revisar el modelo de negocio (Figura 1) y su planificación estratégica (Figura 4), con el objeto de programar un nuevo mix de tiendas y servicios que se adapte a las necesidades y requerimientos de los nuevos clientes. Un ejemplo son los centros existentes que necesitan remodelaciones para incorporar tecnología a sus espacios e innovaciones para competir con el comercio online.

Por ello, el promotor suele programar la revitalización de acuerdo con el vencimiento de los contratos de arrendamiento a largo plazo, de esta manera, surge la oportunidad tanto de renovar el edificio desde el punto de vista técnico y de diseño como también de renovar el mix de tiendas. El reposicionamiento muchas veces puede estar conectado a un plan de extensión de los espacios del centro comercial, que suelen ya estar planificados en las primeras etapas de promoción del centro comercial (Kramer, 2008; Alexander y Muhlebach, 2019).

De este modo, según Alexander y Muhlebach. (2019), para fortalecer el centro comercial se debe tener en cuenta en la estrategia de remodelación su modelo de centro físico, el medio para la futura comercialización y los cambios en las tendencias de la venta de los productos minoristas. Se debe reconsiderar si el centro comercial en formato tradicional ha perdido atractivo, lo que reduce sus opciones como producto de inversión.

En este sentido, resulta relevante el desarrollo de un nuevo marco de relaciones que incorpore los desafíos a los que se enfrenta el sector de retal físico frente a la transformación digital. En este momento, el proceso de promoción vuelve a la etapa de estudio de viabilidad de la fase de predesarrollo (Figura 1), con un nuevo estudio de viabilidad económico, arquitectónico/ técnico y de mercado para definir un producto nuevo.

\section{Conclusiones}

La promoción de un centro comercial implica una secuencia de decisiones económicas, financieras y proyectuales que están fuertemente condicionadas por parámetros temporales, tecnológicos, políticos, sociales y ambientales. En este sentido, el proceso requiere un análisis sistemático de las actividades que lo componen para acotar al máximo los riesgos y maximizar las oportunidades. Sin embargo, no existe una definición unificada de las actividades que componen el proceso.

Desde el punto de vista del inversor, esta situación puede disminuir su margen de beneficio estimado y generar impactos irreversibles en el ciclo de vida del edificio. La falta de un marco estandarizado y claro acerca de las etapas del proceso, obstaculiza la organización del flujo de información, en los

ACE, 14 (4.2) CC BY-ND 3.0 ES | UPC Barcelona, España | Marco teórico para la planificación estratégica y gestión del proceso de promoción de centros comerciales. DOI: http://dx.doi.org/10.5821/ace.14.42.8748 
diferentes niveles jerárquicos del negocio inmobiliario (corporativo - estrategia de desarrollo del negocio - gestión del edificio).

La revisión realizada de las diferentes etapas y actividades del proceso, evidencian carencias de un marco global para el desarrollo integral del proceso de promoción. Para definir el negocio, es necesario planificar los objetivos estratégicos y plasmarlos en el desarrollo de las diferentes actividades que constituye el proceso de promoción. Por ello, la organización del proceso propuesta considera como etapa inicial la planificación estratégica del negocio.

Esta estructura crea una visión integral de todo el proceso de promoción bajo la premisa de la estrategia de la empresa. Este sistema de análisis permite no sólo entender como el desarrollo de las actividades interactúan con la estrategia de negocio, sino también pone de manifiesto las futuras expectativas de los grupos de interés. Por lo tanto, facilitará la consecución de los objetivos definidos por el promotor, intentando visualizar los impactos, oportunidades y puntos débiles que la estrategia genera en el ciclo de vida del negocio. Además, proporciona una visión total de la cadena de valor del edificio, en la que se puede diseñar las acciones pertinentes para la creación de valor.

Cabe destacar que dicho marco puede ayudar a futuras investigaciones en el ámbito del desarrollo estratégico de negocios inmobiliarios, gestión de proyectos y modelos de viabilidad. Su estructura flexible permite a profesionales adaptar el modelo sugerido al proceso de promoción de todo tipo de activo inmobiliario (p.ej. oficinas, hoteles, residenciales).

\section{Autoría}

La primera autora ha conceptualizado la investigación, analizado los documentos para el desarrollo de la investigación y escrito el articulo; la segunda autora ha analizado los documentos para el desarrollo de la investigación y escrito el articulo y el tercer autor ha participado en la estructuración y diseño de la investigación.

Conflicto de intereses: Los autores declaran que no hay conflicto de intereses.

\section{Bibliografía}

Abrudan, I. y Dabija, D. (2009). The lifecycle shopping centres and possible revitalization strategies. Annals of faculty economics. 4(1), 536-541. Recuperado de https://core.ac.uk/download/pdf/26970223.pdf

AECC (2019). Terminología centros comerciales España. Recuperado de http://directoriocentroscomerciales.aedecc.com/terminologia

Alexander, A. y Muhlebach, R. (2019) Shopping center management and leasing. USA, Institue of real estate management.

Berman, B. y Evans, J. R. (2001). Retail Management. 7th. New Jersey, USA: Prentice Hall.

Birrell, G. y Gao, S. (1997). The property development process of phases and their degrees of importance. Trabajo presentado en RICS cutting edge conference. Dublin. 
Brioso, X. (2015). Integrating ISO 21500 Guidance on Project Management, Lean Construction and PMBOK. Procedia Engineering. 123, 76-84. DOI: https://doi.org/10.1016/j.proeng.2015.10.060

Brown, M. y Lubelczyk, M. (2019). The future of shopping centers. Consumer and Retail. Recuperado de https://www.atkearney.com/retail/article/?/a/the-future-of-shopping-centers-article

Bueno, E. (2009). Estrategias en el mundo inmobiliario - dónde y cuándo comprar, qué construir y cómo vender, incluso en la época de crisis. Madrid, España: Ediciones Díaz de Santos.

Casadesus-Masanell, R. y Ricart, J. E. (2010). From Strategy to Business Models and onto Tactics. Long Range Planning, 43(2-3), 195-215. DOI: https://doi.org/10.1016/j.Lrp.2010.01.004

Chesbrough, H. y Rosenbloom, R. S. (2002). The Role of the Business Model in Capturing Value from Innovation: Evidence from Xerox Corporation's Technology Spin-Off Companies. Industrial and Corporate Change, 11(3), 529-555. DOI: https://doi.org/10.1093/icc/11.3.529

Fisher, P. y Collins, T. (1999). The commercial property development process. Property Management, 17(3), 219-230. DOI: https://doi.org/10.1108/02637479910286907

Gambardella, A. y McGahan, A. M. (2010). Business-Model Innovation: General Purpose Technologies and their Implications for Industry Architecture. Long Range Planning, 43(2-3), 267-271. DOI: https://doi.org/10.1016/j.lrp.2009.07.009

Geltner, D. M. Miller, G., Clayton, J. y Eichholtz. P. (2014). Commercial Real Estate: Analysis and investments. OH, USA: Masson. On Course Learning.

Graaskamp, J. A. (1981) Fundamentals of Real Estate Development. Journal of Property Valuation and Investment, 10(3), 619-639. DOI: https://doi.org/10.1108/14635789210031253

ICSC. (2014). Europe Shopping-Centre Classification and Typical Characteristics. Recuperado de https://www.icsc.com/uploads/t07-subpage/Europe-Shopping-Center-Definition-Standard.pdf

ICSC. (2016). The future of the shopping center industry. Vision 2020 Report. Recuperado de https://www.icsc.com/uploads/default/Envision-2020-Report.pdf

ICSC. (2019). The future of the retail space - The role of physical space in the digital-first retail future. Insider Trends report. Recuperado de http://www.insider-trends.com/free-future-of-retail-spacereport/

Kerzner, H. (2001). Project Management - A Systems Approach to Planning, Scheduling, and Controlling. Nova York: John Wiley \& Sons.

Kohlhepp, D. (Abril, 2012). The real estate development matrix. Proceedings from the American Real Estate Society Meetings. St. Petersburg, Rusia.

Kramer, A. (2008). Retail Development Hadbook. Washington D.C, USA: Fourth edition: ULI Development Handbook series.

Kusumowidagdo, A.; Sachari, A. y Widodo, P. (2011). Shoppers' Perception on Physical Condition of Shopping Centers' Atmosphere at Different Lifecycle. International research journal business studies. 5(2), 87-100. Recuperado de https://dspace.uc.ac.id/handle/123456789/726

ACE, 14 (4.2) CC BY-ND 3.0 ES | UPC Barcelona, España | Marco teórico para la planificación estratégica y gestión del proceso 25 de promoción de centros comerciales. DOI: http://dx.doi.org/10.5821/ace.14.42.8748 
Kyriazis, A. y Cloete, C. (2018). Tenant mix in shopping centres: South Africa and the United Kingdom compared. Journal of Business and Retail Management Research, 12(2), 153-162. Recuperado de https://jbrmr.com/cdn/article file/content 25462 18-01-19-09-52-01.pdf

Lowry, J. R. (1997). The Life Cycle of Shopping Centers. Business Horizons, 40(1), 77-86. DOI: https://doi.org/10.1016/S0007-6813(97)90029-X

Magretta, J. (2002). Why business models matter. Harvard Business Review, 80(5), 86-92.

Mckinsey. (2014). The future of the shopping mall. Mckinsey \& Company. Recuperado de https://www.mckinsey.com/business-functions/marketing-and-sales/our-insights/the-future-of-the -shopping-mall

Miles, M. E.; Berens, G. y Weiss, M. (2000) Real estate development process. Washington D.C, USA: ULI Development Handbook series.

Morris, P. y Jamieson, A. (2004). Translating corporate strategy into project strategy: realizing corporate strategy through project management. Pennsylvania, USA: Project Management Institute, Inc.

Neves, J. C.; Motezuma, J. y Laia A. (2009). Análise de Investimentos Imobiliarios. Portugal, Alfragide: Texto Editores.

Osterwalder, A., y Pigneur, Y. (2013). Business Model Generation. Nueva Jersey, USA: Wiley.

Peiser, R. y Halmilton, D. (2012). Professional Real estate development: The ULI guide to the business. Washington D.C, USA: ULI Development Handbook series.

PMBOK. (2011). A Guide to the Project Management Body of Knowledge. PMBOK Guide.

Porter, M. E. y Kramer, M. R. (2006). Strategy and society: The link between competitive advantage and corporate social responsibility. Harvard business review, (84), 78-92. Recuperado de https://www.comfama.com/contenidos/servicios/Gerenciasocial/html/Cursos/Columbia/Lecturas/St rategy-Society.pdf

Reed, R. y Wilkinson, S. (2012). Property development. New York, USA: Routledge.

Rocha Lima, Jr. (1996). Planejamento de shopping centers. Boletim técnico BT/PCC/162. São Paulo, Brasil: Departamento de Engenharia de Construção Civil, Escola Politécnica da Universidade de São Paulo.

Scott, A. (2018). Australian Shopping Centres: Establishing a Conceptual Business Model. Trabajo presentado en: 25th Annual European Real Estate Society Conference. ERES: Conference. Reading, UK.

Shanmugam, R. (2013). Anchor-store quality in malls: an economic analysis. International Journal of Retail \& Distribution Management, 41(2), 90-112. DOI: https://doi.org/10.1108/09590551311304301

Sorescu, A.; Frambach, T.; Singh, J. Rangaswamy, A. y Bridges, C. (2011). Innovations in Retail Business Models. Journal of Retailing, 87(1), S3-S16. DOI: https://doi.org/10.1016/j.jretai.2011.04.005 
Teece, D. J. (2010). Business Models, Business Strategy and Innovation. Long Range Planning, 43(2-3), 172-194. DOI: $\underline{\text { https://doi.org/10.1016/j.Lrp.2009.07.003 }}$

Vernor, J. D. (2009). Shopping Center apprasail and analysis. Chicago, USA. Second edition: Apprasail Institute.

Vieira de Castro, A. y Ramírez, G. M. (2017). La sostenibilidad aplicada a la gestión del patrimonio inmobiliario. Madrid, España: García-Maroto Editores.

White, J. R. y Gray, K. D. (1996). Shopping Center and Other Retail Properties: Investment, Development, Financing and Management. New York, USA: John Wiley and Sons.

Zott, C. y Amit, R. (2010). Business Model Design: An Activity System Perspective. Long Range Planning, 43(2-3), 216-226. DOI: https://doi.org/10.1016/j.lrp.2009.07.004 